\title{
FORMAÇÃO DO COMITÊ DE ÉTICA NO USO DE ANIMAIS DA PONTIFÍCIA UNIVERSIDADE CATÓLICA DO PARANÁ
}

\author{
Constitution of the Ethical Committee for the Use of Animals in \\ the Pontifical Catholic University of Parana
}

\author{
Antonia Maria Binder do Prado ${ }^{1}$ \\ José Ademar Villanova Junior ${ }^{2}$ \\ Gracinda Maria D'Almeida e Oliveira ${ }^{3}$
}

\section{Resumo}

A preocupação com o uso de animais na pesquisa e no ensino é hoje um fato mundial. Bioética não é mais um neologismo desconhecido. Após três décadas do seu surgimento nos EUA, a bioética vem se destacando preponderantemente como um importante ramo da ética aplicada. Diversos fatos apontam o seu desenvolvimento no mundo: um crescimento constante da literatura sobre o tema, diversos fóruns de debate e realização de Congressos Mundiais de Bioética, o surgimento da disciplina de bioética em diversos cursos acadêmicos, a multiplicação das associações de bioética, o aparecimento das comissões de ética e de bioética, assim como dos chamados "códigos de ética", entre outros. A Pontifícia Universidade Católica do Paraná tem realizado um esforço permanente para tornar cada vez mais clara a sua identidade e sua missão. No planejamento estratégico, apresenta de modo explícito o seu caráter ético, cristão e marista. Tais elementos constituem o coração da própria Instituição, o núcleo fundamental para o qual convergem os objetivos, os planos de ação e as metas das atividades universitárias. A preocupação com o transcendente, dentro do amplo diálogo entre a ciência, a cultura e a fé, tem sido permanente objetivo da Universidade. Diante deste contexto, ela clamava pela formação de seu próprio Comitê de Ética no Uso de Animais, buscando estabelecer indicativos éticos para o uso de animais nas atividades acadêmicas.

Palavras-chave: Bioética; Comitê de ética; Pesquisa com animais; Bem-estar animal.

1 Professora Titular da PUCPR, Coordenadora do CEUA - PUCPR, Av. Sete de Setembro, 4699, ap.1601, Batel, CEP 80240-000, Curitiba - PR, tel: (41) 3299-4300, e-mail: antonia.prado@pucpr.br.

2 Professor Substituto da PUCPR, membro do CEUA - PUCPR, Rua Eloy de Assis Fabris, 319, Novo Mundo, CEP 81030-420, CuritibaPR, tel. (41) 3299-4361, e-mail: jose.villanova@pucpr.br

3 Professora Adjunta da PUCPR, Membro do CEUA - PUCPR, Rua Abel Scuissiato, 99, Guaíra, CEP. 80630-020, Curitiba-PR, tel. (41) 3271-2167, e-mail: gracinda.oliveira@pucpr.br. 


\section{Abstract}

The concern with the use of animals in the research and education is today a world-wide fact; bioethics is not an unknown neologism anymore. After three decades of its sprouting in U.S.A., the bioethics is increasingly being distinguished as an important special segment of the applied ethics. Many facts appoint its development in the world: a constant growth of literature on the subject, diverse debate forums and accomplishment of World-wide Congresses of Bioethics, the sprouting of disciplines of bioethics in diverse academic courses, the multiplication of bioethics associations, the appearance of the bioethics and ethics commissions, as well as the "ethic codes", among others. The Pontifical Catholic University of Parana has carried out a permanent effort to let its identity and mission clearer. In the strategical planning, it presents, in explicit way, its ethical, Christian and Marist character. These elements constitute the heart of the proper Institution, the basic nucleus to which converges the objectives, the plans of action and the goals of the university activities. The concern with transcendent, inside of the ample dialogue between science, the culture and the faith, has been permanent University objective, ahead of this context, it clamor for the formation of its proper Ethics Committee on the Use of Animals, searching to establish ethical indicative for the use of animals in the academic activities.

Keywords: Bioethics; Ethical committee; Animal welfare.

\section{Introdução}

A Pontifícia Universidade Católica do Paraná tem realizado um esforço permanente para tornar cada vez mais clara a sua identidade e a sua missão. No planejamento estratégico, apresenta de modo explícito o seu caráter ético, cristão e marista. Tais elementos constituem o coração da própria Instituição, o núcleo fundamental para o qual convergem os objetivos, os planos de ação e as metas das atividades universitárias. Segundo Juliatto (2005), a preocupação com o transcendente, dentro do amplo diálogo entre a ciência, a cultura e a fé, tem sido permanente objetivo da Universidade. Diante deste contexto, ela clamava pela formação de seu próprio Comitê de Ética no Uso de Animais, buscando estabelecer indicativos éticos para o uso de animais nas atividades acadêmicas.

Comitê de Ética no Uso de Animais (CEUA) da PUCPR, fundado em 2003, estabelece uma agenda prática, tendo sua forma de atuação voltada para a promoção do bem-estar animal numa definição maior. De acordo com a intenção que se propõe aqui, que ratifica o pensamento de Tannenbaum (1995), não seria científico e seria intelectualmente suspeito começar qualquer abordagem de bem-estar animal com a visão de que todas as categorias de uso animal são obviamente aceitáveis e que se deve construir uma aprovação delas numa definição maior de bem-estar. De acordo com Levai (1998), um dos registros mais remotos sobre a preservação da fauna terrestre remonta ao Velho Testamento, quando Nóe - segundo o relato bíblico - teria se apressado em salvar em sua arca um casal de cada espécie animal, garantindo, assim, a continuidade da vida face à ameaça do grande dilúvio. Ao correr dos séculos, algumas vozes clamaram, lúcidas, em favor da Natureza, certas de que todos os seres vivos têm o mesmo direito à existência.

É nesse sentido que caminha este Comitê. Ele representa a possibilidade de promover o bem-estar animal e não apenas se tornou mais uma instância burocrática no controle da utilização de animais. Ela avalia projetos de pesquisa, inspeciona animais, garante atendimento veterinário, além de desempenhar um papel educacional no âmbito da experimentação animal, já que serve de consultora para diferentes protocolos medicamentosos, anestésicos e para realização da eutanásia, quando ela é inapelavelmente necessária.

O Comitê de Ética no Uso de Animais passa por um novo desafio. Ampliou o espaço das discussões, atingiu o ensino e observa-se que ainda são raras as iniciativas no ensino de tais abordagens. Conforme Paixão (2001), é, sobretudo, interessante vincular o debate bioético à ciência do bem-estar animal, pois "o que se constitui em bem-estar para um determinado animal" (questão científica) é diferente de saber "como devemos tratar os animais ou por que devemos promover o bem-estar animal" (questão ética). 


\section{Materiais e métodos}

O Comitê de Ética no Uso de Animais (CEUA) da Pontifícia Universidade Católica do Paraná, buscando estabelecer indicativos éticos para o uso de animais nas atividades acadêmicas de nossa Instituição, resolve apresentar como louvável a atitude daquele que:

a) Aceita a vida como um dom precioso, por isso trata com respeito e responsabilidade cada ser vivo.

b) Não provoca num outro ser vivo dor, desconforto e angústia, que não sejam plenamente justificados.

c) Intensifica o esforço de reduzir o número de animais envolvidos na atividade acadêmica.

d) Mantém-se solícito e cuidadoso frente à incapacidade de defesa ou a fuga dos animais no momento da sua utilização.

e) Aplica método indolor e que não causa estresse, toda vez que, justificadamente, praticar a eutanásia em animais utilizados.

f) Lida com os animais com competência, evitando fazer qualquer procedimento para o qual não esteja tecnicamente preparado.

g) Investiga, criativamente, métodos alternativos à utilização de animais nas atividades acadêmicas.

h) Admite somente condições de manuseio e translado adequados à cada espécie envolvida.

\section{Resultados e discussão}

A Pontifícia Universidade Católica do Paraná, na Sala de Sessões do Conselho Universitário, do Câmpus Curitiba, aos dezenove dias do mês de abril de dois mil e seis, regulamenta a resolução 23/2006 do CONSUN.

\section{RESOLUÇÃO 23/2006}

\section{CAPÍTULO I - DISPOSIÇÕES PRELIMINARES:}

Artigo $1 .^{\circ}$ - Este Regulamento disciplina a constituição, atribuições e funcionamento do Comitê de Ética no Uso de Animais da PUCPR CEUA.
Artigo $2 .^{\circ}-$ O CEUA é um colegiado interdisciplinar e independente, com múnus público, de caráter consultivo, deliberativo e educativo, criado para defender os animais utilizados - como modelos e como finalidade - na pesquisa, no ensino e na extensão, salvaguardando seus direitos e dignidade compatíveis com suas próprias espécies e para contribuir no aprimoramento ético das atividades a que forem submetidos.

Artigo $3 .^{\circ}$ - Toda atividade de pesquisa, ensino e extensão, vinculada à PUCPR e à entidades conveniadas envolvendo animais, deve ser submetida à apreciação deste Comitê.

Parágrafo único - O CEUA pode apreciar projetos de pesquisa envolvendo animais, de iniciativa de profissionais de outros hospitais, ou outras unidades de saúde e instituições, caso nestas instituições não haja um CEUA devidamente instituído.

\section{CAPÍTULO II - COMPOSIÇÃO}

Artigo $4 .^{\circ}$ - O CEUA, face à sua especificidade, deve ser constituído por um colegiado de, no mínimo, sete membros, com a participação de profissionais das áreas de Ciências Agrárias, Ciências Biológicas, Sociais e Humanas, sendo, pelo menos, um membro da comunidade.

$\S 1 .^{\circ}$ - O CEUA tem caráter multi e transdisciplinar, com a participação de homens e mulheres, não devendo haver mais que a metade de seus membros pertencentes à mesma categoria profissional.

$\S 2 .^{\circ}$ - Na composição do CEUA deve ter, necessariamente, ao menos um representante dos seguintes segmentos: curso de graduação em Medicina Veterinária; curso de graduação em Zootecnia; curso de graduação em Agronomia; curso de graduação em Biologia; curso de graduação em Odontologia; curso de graduação em Medicina; Núcleo de Estudos em Bioética - NEB; uma entidade representativa de defesa dos animais devidamente constituída.

$\$ 3 .^{\circ}-$ É recomendável que os seguintes segmentos sejam representados no CEUA: cursos de graduação que utilizam animais na pesquisa ou ensino; docentes dos programas de pós-graduação stricto sensu dos centros afins; entidades conveniadas com a PUCPR e que utilizem animais em suas atividades; o Centro de Ciências Jurídicas e 
Sociais - CCJS; o Centro de Teologia e Ciências Humanas - $\mathrm{CTCH}$; discentes de programas de doutorado.

$\$ 4 .^{\circ}$ - O CEUA pode contar com consultores, pertencentes ou não à Instituição, com a finalidade de analisar projetos de pesquisa e/ou fornecer subsídios técnicos ao colegiado, quando de suas deliberações.

\section{CAPÍTULO III - INDICAÇÃO DOS MEMBROS E MANDATO}

Artigo $5 .^{\circ}$ - Os membros do CEUA são indicados pela direção do curso, setor ou unidade que representa.

Parágrafo único - A nomeação dos membros do CEUA é feita por ato do Reitor da PUCPR. Artigo $6 .^{\circ}-$ O mandato dos membros do CEUA tem a duração de três anos, podendo ser reconduzidos dois terços de seus componentes.

Artigo $7 .^{\circ}$ - Os trabalhos do Comitê são dirigidos por um Coordenador escolhido dentre os seus componentes, cujo mandato tem a duração de três anos, permitida a recondução.

Parágrafo único - As escolhas do coordenador, vice-coordenador e secretário são atribuídas a seus pares, quando da realização da primeira reunião de trabalho do CEUA, no início de cada mandato.

\section{CAPÍTULO IV - LIBERDADE DE TRABALHO E ISENÇAO}

Artigo $8 .^{\circ}$ - Os membros do CEUA têm independência nas tomadas de decisão relativas a suas funções, respeitando a legislação vigente e as normas institucionais, mantendo sob caráter confidencial as informações recebidas, não podendo sofrer qualquer tipo de pressão quando de suas deliberações, quer de superiores hierárquicos, quer de interessados nas atividades sob apreciação, devendo isentar-se, por outro lado, de envolvimento financeiro e de conflito de interesses delas decorrentes.

\section{CAPÍTULO V - COMPETÊNCIA}

Artigo 9. - Para as atividades relacionadas ao ensino, pesquisa e extensão, é da competência do colegiado do CEUA:
I. Recomendar aos docentes e discentes que observem as normas vigentes no país e as orientações definidas por este Comitê, quando utilizarem animais nas suas atividades.

II. Solicitar aos Diretores de Curso de Graduação e Pós-Graduação da PUCPR a relação dos programas de aprendizagem ou disciplinas, que utilizam animais nas atividades de ensino, pesquisa e extensão nos seus respectivos cursos, nomeando os docentes ou outros responsáveis.

III. Recomendar aos docentes que encaminhem ao Comitê protocolo solicitando parecer a respeito das atividades que envolvem o uso de animais em seus programas de aprendizagem ou disciplinas, comunicando qualquer alteração que venha a ocorrer relativa à metodologia, número de animais usados ou substituição de docentes.

IV. Apreciar os protocolos de pesquisa envolvendo animais na PUCPR, cuja apreciação não pode ser dissociada de análise científica, cabendo-lhe a responsabilidade primária pelas decisões sobre a ética, de modo a garantir e resguardar os direitos e a dignidade dos animais compatíveis com sua espécie.

V. Acolher e apreciar, igualmente, quando for o caso, e mediante os mesmos critérios, os protocolos relativos a pesquisas originárias de outras instituições, e/ou de pesquisadores responsáveis, que lhe forem submetidos e que forem julgadas passíveis de apreciação.

VI. Solicitar aos biotérios da PUCPR e entidades conveniadas que utilizem animais nas suas atividades que submetam os seus procedimentos internos, no tocante ao cuidado de animais e à sua liberação para atividades de ensino, pesquisa e extensão, à apreciação do Comitê.

VII. Emitir parecer consubstanciado por escrito, no prazo máximo de 30 (trinta) dias, a partir da data do conhecimento formal do protocolo, o qual culminará com o seu enquadramento em uma das seguintes categorias:

a) Aprovado.

b) Aprovado com recomendação, quando o CEUA considerar o protocolo aceitável, cujas atividades podem se iniciar, porém nele identificar algum problema sanável, caso em que deve ser devolvido à origem, recomendando uma revisão específica ou solicitando uma modificação e/ou informação relevante, que deve ser objeto de atendimento pelo(s) docente(es) no prazo máximo de 30 (trinta) dias contados da data em que dela tomar(em) conhecimento. 
c) Com pendência, quando o CEUA considerar o protocolo inaceitável, cujas atividades não podem se iniciar, por nele identificar algum problema sanável, caso em que deve ser devolvido à origem, recomendando uma revisão específica ou solicitando uma modificação e/ou informação relevante, que deve ser objeto de atendimento pelo(s) docente(es) no prazo máximo de 60 (sessenta) dias contados da data em que dela tomar(em) conhecimento, sendo que transcorrido este prazo o protocolo será retirado da apreciação do colegiado.

d) Não aprovado.

Os pareceres aprovados relacionados às atividades de ensino e extensão precisam ser renovados a cada 2 (dois) anos.

VIII. Acompanhar o desenvolvimento dos projetos mediante relatórios anuais e/ou finais dos pesquisadores, considerando-se como antiétic, a descontinuidade não justificada perante o CEUA, de pesquisa por ele aprovada.

IX. Manter a guarda confidencial de todos os dados obtidos no desempenho de suas atribuições, devendo providenciar o arquivamento do protocolo completo após a sua aprovação, que ficará à disposição das autoridades sanitárias.

$\mathrm{X}$. Desempenhar papel consultivo e educativo em relação a todos os interessados nas atividades envolvendo animais na PUCPR ou fora dela quando for o caso, fomentando a reflexão em torno da ética na ciência.

XI. Receber denúncias de abusos ou notificação sobre fatos adversos que possam alterar o curso normal das atividades, decidindo, quando for o caso, pela sua continuidade, modificação ou suspensão.

XII. Vistoriar as atividades que foram objetos de avaliação do CEUA.

XIII. Requerer à Pró-Reitoria de Graduação, Pesquisa e Pós-Graduação procedimento administrativo disciplinar, sindicância ou processo administrativo em caso de denúncia ou comprovação de irregularidade de natureza ética em atividades envolvendo animais realizadas no âmbito da Instituição ou das entidades conveniadas, nos termos do Artigo 131 e seguintes do Regimento Geral da PUCPR.
XIV. Manter comunicação regular e permanente com órgãos que gerenciam ou venham a gerenciar as atividades envolvendo animais no país.

\section{CAPÍTULO VI - FUNCIONAMENTO}

Artigo 10 - O CEUA realiza sessões ordinárias, nas dependências da Instituição, ao longo do período letivo, e sessões extraordinárias sempre que se fizer necessário, em ambos os casos, com o número mínimo de cinco de seus componentes, presentes para o início dos trabalhos. Parágrafo único - As sessões do CEUA são registradas em atas pelo Secretário, que assinadas por ele, em conjunto com o Coordenador, são objeto de apreciação pelos membros do colegiado, nas reuniões subseqüentes àquelas a que se referirem.

Artigo 11 - As decisões do CEUA são proferidas por maioria simples, cabendo ao coordenador o voto de qualidade no caso de empate.

Artigo 12 - O membro do CEUA que, sem justificativa, faltar a três sessões de trabalho no mesmo ano letivo, consecutivas ou não, dele será excluído.

Parágrafo único - A substituição do membro excluído far-se-á nas mesmas condições estabelecidas para escolha de membro do CEUA, neste Regulamento.

Artigo 13 - Todas as entidades ligadas à Associação Paranaense de Cultura e que utilizem animais em suas atividades de ensino, pesquisa e extensão deverão, mediante convênio, submeter seus projetos à apreciação do CEUA.

Artigo 14 - Os casos omissos neste Regulamento serão dirimidos pelo Colegiado do CEUA e referendados pela Pró-Reitoria de Graduação, Pesquisa e Pós-Graduação.

Artigo 15 - Este Regulamento entra em vigor a partir desta data, revogadas as disposições em contrário.

\section{ATIVIDADES DO CEUA DE 2004 A 2006}

Com a regulamentação das atividades do CEUA, teve início a submissão e avaliação de projetos de pesquisa envolvendo animais. De julho de 2004 a dezembro de 2006 foram avaliados 190 projetos, apresentados na tabela 1. 


\section{TABELA 1 - Projetos submetidos à avaliação do CEUA.}

Table 1 - Projects submitted to the CEUA appreciation.

\begin{tabular}{|c|c|c|c|c|c|}
\hline \multirow{2}{*}{ Ano } & \multirow{2}{*}{$\begin{array}{c}\text { N. }{ }^{\circ} \\
\text { projetos }\end{array}$} & \multicolumn{2}{|c|}{ Aprovados $^{\mathbf{1}}$} & \multicolumn{2}{c|}{ Não aprovados $^{\mathbf{2}}$} \\
\cline { 3 - 6 } & & $\mathbf{N} .^{\circ}$ total & \% & N. ${ }^{\circ}$ total & \% \\
\hline 2004 & 50 & 44 & 88 & 06 & 12 \\
2005 & 63 & 57 & 90,5 & 06 & 9,5 \\
2006 & 77 & 68 & 88,3 & 09 & 11,7 \\
\hline
\end{tabular}

1 Projetos aprovados integralmente e com pendências (sujeitos a readequações que não comprometem a ética) 2 Projetos retirados, não aprovados e não reapresentados.

\section{Conclusões}

Segundo Urban (2003), o século XX foi a época na história da humanidade em que mais se falou do homem e dos direitos humanos. Enfocamos, como ele, que sob o domínio quase exclusivo da Economia e da Política, esse também foi o tempo em que se verificaram as maiores violações desses mesmos direitos e uma perda do senso do homem e de suas relações com a sociedade.

Reafirmamos, conforme foi defendido por Sanches (2004), na era pós-genômica, que não se pode negar que o desenvolvimento da ciência seja um fato. Isso não quer dizer que ele acontece independentemente das decisões humanas, mas significa, pelo contrário, que cientistas têm dedicado grande parte de suas energias à pesquisa. Cabe aí o desenvolvimento simultâneo de uma sensibilidade bioética, algo que não pode estar ausente, e que, verdadeiramente, interessa neste diálogo: a defesa da vida na terra.

Mais do que assunto de discussão ou reclamação, o tema do uso de animais na pesquisa e no ensino vem se tornando objeto de preocupação. Sobram motivos que justificam tal atitude. Nesse ponto, parece haver pouca discordância. A matéria desassossega educadores, estudantes, autoridades governamentais e pessoas preocupadas com o bem-estar animal. A questão deixou de ser debatida apenas nos círculos acadêmicos e passou também a ocupar amplo espaço na mídia, dada a sua relevância por toda sociedade.

O uso de animais em experimentos científicos e atividades didáticas são necessários, especialmente para o avanço dos conhecimentos na área da saúde do homem e dos animais. Os profissionais envolvidos no manejo de animais de experimentação devem ter sempre consciência de que os animais são seres sencientes e que possuem sensibilidade similar à humana no que se refere à dor, memória, angústia e instinto de sobrevivência. Os animais utilizados como modelos experimentais são seres vivos que possuem as mesmas características biológicas dos outros animais de sua espécie, com a diferença de estarem sendo privados de sua liberdade em favor da Ciência. Portanto, devem ser manejados com respeito e de forma adequada à espécie, tendo suas necessidades de transporte, alojamento, condições ambientais, nutrição e cuidados veterinários atendidos. A observância de princípios e critérios para a utilização de animais em experimentos científicos e atividades didáticas tem por objetivo monitorar o uso de modelos animais. Os projetos de pesquisa que utilizam modelos animais devem ser analisados por Comitês de Ética em Pesquisa ou colegiados similares, visando à qualificação dos projetos e evitando o uso inapropriado ou abusivo de animais em experimentação.

Na Tabela 1, apresentada anteriormente, verifica-se que o número de projetos submetidos ao CEUA-PUCPR sofreu um acréscimo significativo (50\%), considerando-se número de projetos avaliados em 2004 e 2006. Tal fato sugere que a comunidade acadêmica está preocupada com a ética no uso de animais, conforme tem sido a tendência a nível mundial. 
Outro fato que merece destaque é a pequena variação no percentual de projetos não aprovados no triênio, mesmo com o acréscimo no número total de projetos apresentados. Considerase, portanto, que o CEUA, além de sua função avaliativa, tem conseguido exercer ação educativa, preventiva e propagadora da ética dentro da Instituição.

\section{Referências}

JULIATTO, C. I. A Universidade em Busca da Excelência. Curitiba: Champagnat, 2005.

LEVAI, L. L. Direito dos animais: O direito deles e o nosso Direito sobre eles. São Paulo, SP: Mantiqueira, 1998.
PAIXÃO, R. L. Bioética e Medicina Veterinária: um encontro necessário. In: Revista do Conselho Federal de Medicina Veterinária. Brasília, Conselho Federal de Medicina Veterinária, ano 7, n. 23, mai/jun/jul/ago, p. 20-26, 2001.

SANCHES, M. A. Bioética: Ciência e Transcendência. São Paulo, SP: Loyola, 2004.

TANNENBAUM, J. Veterinary Ethics: Animal welfare, client relations, competition and collegiality. Missoury: Mosby-Year, 1995.

URBAN, C. A. Bioética Clínica. Rio de Janeiro, RJ: Revinter, 2003. 